\title{
Optical properties of ultraphosphate glasses containing mixed divalent zinc and magnesium ions
}

\begin{abstract}
Ternary zinc magnesium ultraphosphate glasses corresponding to $(\mathrm{ZnO}) \mathrm{x}(\mathrm{MgO}) 30-\mathrm{x}(\mathrm{P} 2 \mathrm{O} 5) 70$ were prepared by melt quenching technique in the range of 5 $\leqslant x \leqslant 20 \mathrm{~mol} \%$. The optical absorption spectra of the glasses were measured at room temperature in the wavelength range between 190 and $1100 \mathrm{~nm}$, and the refractive indices of the glasses were measured at room temperature at a wavelength of $632.8 \mathrm{~nm}$. The optical absorption spectra indicated that the electronic transition was indirect and associated with the phonon-assisted transition. From the absorption spectra, the optical energy band gap (Eopt) and Urbach energy (EU) values for all of the glass samples were calculated from their ultraviolet edges. The values of Eopt and EU were found to be in the range of 3.54$3.81 \mathrm{eV}$ and $0.27-0.45 \mathrm{eV}$, respectively, both of which vary in a non-linear manner, with a turning point at $15 \mathrm{~mol} \%$ of $\mathrm{ZnO}$. The composition-dependence of these values has been suggested and analyzed in the light of switching role of $\mathrm{Mg} 2+$ based on its anomalous natural behavior from network builder to modifier depending upon its concentration. The values of refractive index ranged from 1.513 to 1.534. Variations in these optical parameters, as well as variations in density and molar volume are discussed and correlated with the structural changes within the glassy matrix.
\end{abstract}

Keyword: Optical properties; Phosphate glasses; Refractive index. 